при повышенной температуре происходит ускорение процессов, в связи с чем увеличивается разрядная емкость ХИТ.

Результаты циклирования показали увеличение емкости и напряжения ХИТ при более высокой температуре по сравнению с нормальной. Полученная зависимость позволяет в процессе проведения УКИ отслеживать фактическую емкость ХИТ и с помощью математической модели приводить разрядные характеристики ХИТ, полученные при повышенной температуре, к нормальной.

Проведенные УКИ в полной мере обеспечивают определения характеристик ХИТ с целью подтверждения возможности их использования в составе систем электроснабжения.

\section{Библиографические ссылки}

1. Хрусталев Д.А. Аккумуляторы. Москва : Изумруд, 2003. 224 с.

2. Вырыпаев В.Н. и др. Химические источники тока : уч. пособ. для хим.технол. спец. вузов. Москва : Высш. шк., 1990. $240 \mathrm{c}$.
3. Накопители энергии : учеб. пособие для вузов / Д.А. Бут, Б.Л. Алиевский, С.P. Мизюрин, П.В. Васюкевич. Москва Энергоатомиздат, 1991. 400 с.

4. Земляной К.Н., Рева В.С., Фролов В.П. Анализ режимов работы и выбор химического источника тока из состава систем электроснабжения самоходной пусковой установки. Космическая техника. Ракетное вооружение. 2016. № 2. С. 52-56.

5. Давидов. А.О. Основные эксплуатационные параметры и классификация режимов работы электрохимических аккумуляторов. Авиационно-космическая техника и технология. 2011. № 7 (84). С. 120-125.

6. Клочкова. Л.Л., Щербаков А.Н. Оценка характеристики энергоустановок с ХИТ на ранней стадии проектирования: учеб. пособие. Москва : Изд-во МАИ, 1993. $76 \mathrm{c}$.

Надійшла до редколегії 01.07.2018 p.

\title{
ОПРЕДЕЛЕНИЕ ДЕФОРМИРОВАНИЯ ИСХОДНОГО ПРЯМОУГОЛЬНОГО СЕЧЕНИЯ ПРОФИЛЬНЫХ ЗАГОТОВОК ПРИ ИЗГОТОВЛЕНИИ ГИБКОЙ ЭЛЕМЕНТОВ КОНСТРУКЦИЙ ИЗДЕЛИЙ АЭРОКОСМИЧЕСКОЙ ТЕХНИКИ ТИПА ШПАНГОУТ
}

Е.Г. Седачова ${ }^{1}$, А.В. Кулик ${ }^{2}$ Н.Н. Убизький ${ }^{2}$

${ }^{1}$ Днепровский колледж ракетно-космического машиностроения

2 Днепровский национальный университет имени Олеся Гончара

Розроблено математичну модель для визначення деформування прямокутного перетину заготовок при згинанні. перетину.

Ключові слова: згинання, заготовки, прямокутний перетин, деформування прямокутного

The worked out mathematical model is for determination of deformation of the rectangular crossing of purveyances at bending.

Keywords: bending, purveyances, rectangular crossing, deformation of the rectangular crossing.

Разработана математическая модель для определения деформирования исходных прямоугольных сечений заготовок при изгибе.

Ключевые слова: гибка, заготовки, прямоугольное сечение, деформирование прямоугольного сечения.

Постановка задачи. При изготовлении элементов конструкций ротационной гибкой из заготовок, имеющих исходное прямоугольное сечение. наряд $\mathrm{c}$ основным (C) Седачова Е.Г., Кулик А.В., Убизький Н.Н., 2018 формоизменением заготовок - приданием требуемой кривизны, имеет место искажение формы поперечного сечения. Боковые стороны сечения поворачиваются, оставаясь прямыми, а две другие стороны 
искривляются (рис. 1). Длина заготовок, как правило, во много раз больше размеров поперечного сечения, депланация торцов невелика и практически не влияет на распределение тангенциальных деформаций, поэтому поверхность нулевых тангенциальных деформаций считается цилиндрической, её радиус $\mathrm{R}$ значительно больше Н. Аналитическое определение искажения формы исходного прямоугольного поперечного сечения заготовки после изгиба на радиус $\mathrm{R}$ представляет значительные трудности, поэтому используется численное математическое моделирование.

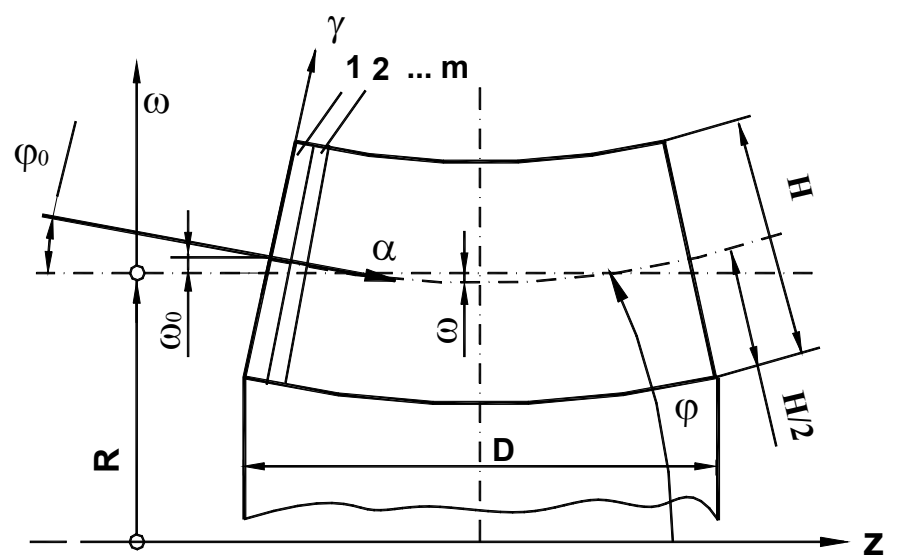

Рис. 1. Изменение формы поперечного сечения заготовок при изгибе

Основная часть. Разобьем половину поперечного сечения заготовки на $\mathrm{m}$ элементов, размеры которых $\mathrm{H}$ и $1_{\mathrm{m}}=\mathrm{D} /(2 \mathrm{~m})$ неизменны. Первый элемент под номером 1 расположен на краю поперечного сечения, а элемент с номером m граничит с осью симметрии (см. рис. 1).

Механизм изменения формы поперечного сечения заключается в следующем. Средняя линия поперечного сечения начинает искривляться одновременно с изгибом заготовки, т.е. последняя приобретает поперечную кривизну. Пока напряженное состояние заготовки остаётся линейным, её поперечная кривизна равна по абсолютной величине половине продольной [1]. По мере уменьшения радиуса заготовки R (см. рис. 1) увеличивается прогиб $\omega$ образующей срединной поверхности относительно нейтральной линии. В результате оказывается, что на краях поперечного сечения высота области растяжения $\mathrm{H} / 2+\omega$ существенно больше высоты области сжатия $\mathrm{H} / 2-\omega$, а в центре, где прогиб $\omega$ отрицателен, превалируют сжимающие деформации. Продольная сила $\mathrm{N}_{2}$, действующая на элементы, становится положительной на краях поперечного сечения и отрицательной в центре. Под

действием силы $\mathrm{N}_{2}$ в широтных сечениях возникают перерезывающая сила $\mathrm{Q}_{1}$ момент $\mathrm{M}_{1}, \quad$ противодействующие поперечному изгибу заготовки. Напряженное состояние перестаёт быть линейным.

Математическое моделирование данного процесса затруднительно тем, что на краю поперечного сечения заготовки можно задать лишь часть граничных условий: $\sigma_{\alpha}=0 ; \quad \mathrm{Q}_{1}=0 ; \mathrm{M}_{1}=0$; $\mathrm{k}_{1}=-1 /(2 \mathrm{R})[2]$.

Остальные два граничных условия могут быть проверены после расчета всех элементов:

$$
\varphi_{\mathrm{m}+1}=0, \quad \mathrm{P}=1 \mathrm{~m} \sum_{\mathrm{i}=1}^{\mathrm{m}} \mathrm{N}_{2 \mathrm{i}}=0 .
$$

Последнее из двух условий означает, что суммарная продольная сила, действующая на половину поперечного сечения заготовки, принимается равной нулю. Для расчета искажения поперечного сечения необходимо

задать взаимозависимые параметры, а именно: радиус гибки $\mathrm{R}$, угол наклона $\varphi_{1}$, прогиб образующей срединной поверхности заготовки на краю поперечного сечения $\omega_{1}$.

Математическое изменения параметров моделирование прямоугольного 
поперечного сечения невозможно без задания параметров $\omega_{1}$ и $\varphi_{1}$, так как именно от прогиба образующей срединной поверхности зависит значение внутренней силы, приходящейся на элемент.

Итерационным методом решается система уравнений равновесия сил и моментов для элементов заготовки [3]. Один из взаимосвязанных параметров $\mathrm{R}$ задаём, остальными параметрами $\omega_{1}$ и $\varphi_{1}$ варьируем. Критерием правильности значений $\omega_{1}$ и $\varphi_{1}$ служит выполнение граничных условий (1). Положительные направления $\varphi$ и $\omega$ показаны на рис.1. После расчета последнего элемента под номером т проверяем условия (1).

В табл. 1 приведены дискретные значения проверяемых параметров $\varphi_{\mathrm{m}+1}$ и $\mathrm{P}$, соответствующие различным значениям варьируемых параметров $\omega_{1}$ и $\varphi_{1}$.

Размерность $\mathrm{P}-\mathrm{H}, \omega_{1}-\mathrm{Mм}, \varphi_{1}$ и $\varphi_{\mathrm{m}+1}$ - рад. Использовались следующие исходные данные: D $=80$ мм., H $=10$ мм,
$\mathrm{R}=100$ мм, материал заготовки - АД1, шаг варьирования $\omega_{1}$ и $\varphi_{1}+$ соответственно 0,1 мм и 0,01 рад. В каждой строке табл. 1 наиболее близкие к нулю значения $\varphi_{\mathrm{m}+1}$ и $\mathrm{P}$ помечены полужирным шрифтом. Согласно данным табл. 1 искомые значения варьируемых параметров с точностью к шагу варьирования составляют $\omega_{1}=1,8$ мм, $\varphi_{1}=-0,15$ рад.

Изложенная процедура итерационного вычисления $\varphi_{1}$ и $\omega_{1}$ может применяться без предварительного составления таблицы, подобной табл. 1. Изменим, например, в исходных данных, которые использовались при расчете табл. 1, ширину заготовки с 80 мм на 100 мм и решим систему уравнений (1) с помощью итерационной процедуры приведенной в табл. 2.

В табл. 3 приведены рассчитанные в 3-й итерации значения меридиональной кривизны заготовки, осредненные в пределах элемента при ширине заготовки D $=100 \mathrm{MM}$.

Таблица 1

Расчетные значения угла наклона средней линии поперечного сечения заготовки в плоскости симметрии $\varphi_{\mathrm{m}+1}$ (верхние числа) и продольной силы $\mathrm{P}$ (нижние числа)

\begin{tabular}{|c|c|c|c|c|c|c|c|c|}
\hline \multirow{2}{*}{$\omega_{1}$} & \multicolumn{7}{|c|}{$\varphi_{\mathrm{m}+1} /$ Р при $\varphi_{0}$} \\
\cline { 2 - 9 } & $-0,10$ & $-0,13$ & $-0,14$ & $-0,15$ & $-0,16$ & $-0,18$ & $-0,20$ & $-0,22$ \\
\hline \multirow{2}{*}{1,5} & 0,044 & 0,033 & 0,030 & 0,025 & 0,019 & 0,013 & 0,004 & $\mathbf{0 , 0 0 1}$ \\
& 6140 & $\mathbf{1 4 1 0}$ & -1720 & -3320 & -3970 & -8190 & -11350 & -14600 \\
\hline \multirow{2}{*}{1,6} & 0,033 & 0,028 & 0,024 & 0,022 & 0,016 & 0,005 & $\mathbf{- 0 , 0 0 1}$ & $-0,008$ \\
& 7560 & 1800 & $\mathbf{- 3 4 0}$ & -2800 & -3620 & -7380 & -10660 & -13880 \\
\hline \multirow{2}{*}{1,7} & 0,022 & 0,018 & 0,013 & 0,012 & 0,010 & $\mathbf{- 0 , 0 0 2}$ & $-0,007$ & $-0,015$ \\
& 8690 & 2420 & $\mathbf{7 4 0}$ & -1980 & -3110 & -6440 & -9740 & -12970 \\
\hline \multirow{2}{*}{1,8} & 0,014 & 0,008 & 0,003 & $\mathbf{0 , 0 0 0}$ & $-0,002$ & $-0,008$ & $-0,018$ & $-0,026$ \\
& 9180 & 3030 & 1690 & $\mathbf{- 9 7 0}$ & -2260 & -6000 & -8760 & -12030 \\
\hline \multirow{2}{*}{1,9} & 0,009 & $\mathbf{0 , 0 0 0}$ & $-0,006$ & $-0,011$ & $-0,013$ & $-0,016$ & $-0,027$ & $-0,035$ \\
& 9560 & 3580 & 2570 & $\mathbf{- 1 1 0}$ & -1460 & -5260 & -7830 & -11440 \\
\hline \multirow{2}{*}{2,0} & $\mathbf{0 , 0 0 3}$ & $-0,005$ & $-0,010$ & $-0,014$ & $-0,020$ & $-0,026$ & $-0,035$ & $-0,042$ \\
& 10000 & 4120 & 3310 & $\mathbf{6 2 0}$ & -810 & -4290 & -7210 & -10900 \\
\hline
\end{tabular}


Итерационная процедура решения системы уравнений (1) при ширине заготовки D = 100 мм

\begin{tabular}{|c|c|c|c|c|c|c|}
\hline № итерации & 0 & 1 & 1 & 2 & 2 & 3 \\
\hline$\omega_{0}$, мм & 1,800 & 1,972 & 1,972 & 1,996 & 1,996 & 2,002 \\
\hline$\varphi_{0}$, мм & $-0,1413$ & $-0,1413$ & $-0,1453$ & $-0,1453$ & $-0,1458$ & $-0,1458$ \\
\hline$\varphi_{\mathrm{m}+1}$, рад & 0,026684 & 0,000013 & 0,003537 & 0,000498 & 0,000963 & 0,000148 \\
\hline $\mathrm{P}, \mathrm{H}$ & $-11,7$ & 2808,1 & $-127,0$ & 296,4 & $-75,7$ & 30,1 \\
\hline
\end{tabular}

Таблица 3

Рассчитанные в 3-й итерации значения меридиональной кривизны заготовки, осредненные в пределах элемента при ширине заготовки $D=100$ мм

\begin{tabular}{|c|c|c|c|}
\hline № элемента & Кривизна $\mathrm{k}_{1}, \mathbf{M}^{-1}$ & № элемента & ${\text { Кривизна } \mathrm{k}_{1}, \mathbf{M}^{-1}}^{-1}$ \\
\hline 1 & $-4,98$ & 11 & $-2,71$ \\
\hline 2 & $-4,91$ & 12 & $-2,43$ \\
\hline 3 & $-4,76$ & 13 & $-2,16$ \\
\hline 4 & $-4,57$ & 14 & $-1,91$ \\
\hline 5 & $-4,34$ & 15 & $-1,69$ \\
\hline 6 & $-4,09$ & 16 & $-1,33$ \\
\hline 7 & $-3,82$ & 17 & $-1,20$ \\
\hline 8 & $-3,55$ & 18 & $-1,11$ \\
\hline 9 & $-3,27$ & 10 & $-1,07$ \\
\hline
\end{tabular}

Выводы. При численном расчете искажения предусматривать проверку сходимости вычислений корней системы уравнений (1). Если вычисления расходятся, итерационная процедура изменяется: параметр $\varphi_{0}$ определяется из 2-го уравнения (1), а параметр $\omega_{0}-$ из 1-го уравнения (1).

Определение деформирования исходного прямоугольного сечения профильных заготовок при изготовлении гибкой элементов конструкций изделий аэрокосмической техники типа шпангоут позволяет повысить точность технологических расчётов и учесть это деформирование для обеспечения стыковочных диаметральных размеров.

\section{Библиографические ссылки}

1. Хилл Р. Математическая теория пластичности. Москва : Изд-во ГИТТЛ, 1956. $407 \mathrm{c}$.

2. Власов В.3. Общая теория оболочек и ее применение в технике. Избранные трудыл. Москва : Изд-во АН СССР, 1962. Т. $1.528 \mathrm{c}$.

3. Калиткин Н.Н. Численные методы. Москва : Наука, 1978. 512 с.

Надійшла до редколегії 21.05.2018 p

УДК 621.454.2.046.2

\title{
ЭКСПЕРИМЕНТАЛЬНОЕ ПОДТВЕРЖДЕНИЕ РАБОТОСПОСОБНОСТИ КАПИЛЛЯРНОГО ЗАБОРНОГО УСТРОЙСТВА (СЕТЧАТОГО РАЗДЕЛИТЕЛЯ) ПРИ ПРОГРАММНОМ РАЗВОРОТЕ
}

\author{
И.В. Седых, Д.Э. Смоленский, Д.С. Назаренко
}

ГП «КБ «Южное» им М.К. Янгеля», ул. Криворожская, 3, г. Днепр, 49010, Украина, e-mail:bers_1@ukr.net

Однісю 3 проблем забезпечення групового виведення космічних апаратів с забезпечення повторного запуску маршового двигуна для переходу на іншу орбіту, після відділення першого апарату. При програмному розвертанні ступінь відчуває прискорення різноманітного напрямку, що призводить до відтоку компонента палива від сіткового роздільника. Це, в свою чергу, призводить до оголення 